\title{
Assessment of ${ }^{222}$ radon progeny loss in long tubing based on static filter measurements in the laboratory and in the field
}

\author{
Ingeborg Levin ${ }^{1}$, Dominik Schmithüsen ${ }^{1}$, and Alex Vermeulen ${ }^{2, a}$ \\ ${ }^{1}$ Institut für Umweltphysik (IUP), Heidelberg University, 69120 Heidelberg, Germany \\ ${ }^{2}$ Energy research Centre of the Netherlands (ECN), 1755LE Petten, the Netherlands \\ ${ }^{a}$ now at: ICOS ERIC, Carbon Portal, Lund, Sweden
}

Correspondence to: Ingeborg Levin (ingeborg.levin@iup.uni-heidelberg.de)

Received: 1 April 2016 - Discussion started: 30 June 2016

Revised: 6 October 2016 - Accepted: 16 October 2016 - Published: 3 April 2017

\begin{abstract}
Aerosol loss in air intake systems potentially hampers the application of one-filter systems for progeny-based atmospheric ${ }^{222}$ radon $\left({ }^{222} \mathrm{Rn}\right)$ measurements. The artefacts are significant when air has to be collected via long sampling lines, e.g. from elevated heights at tall tower observatories. Here we present results from a study, determining ${ }^{222} \mathrm{Rn}$ progeny loss from ambient air sampled via $8.2 \mathrm{~mm}$ inner diameter (ID) Decabon tubing in the laboratory and from pre-installed $10 \mathrm{~mm}$ ID tubing at the Cabauw meteorological tower in the Netherlands. Progeny loss increased steeply with length of the tubing, decreasing sampling efficiency to $66 \%$ for $8.2 \mathrm{~mm}$ ID rolled-up tubing of $200 \mathrm{~m}$ length at a flow rate of ca. $1 \mathrm{~m}^{3} \mathrm{~h}^{-1}$. Preliminary theoretical estimation of the loss yielded a sampling efficiency of $64 \%$ for the same tubing, when taking into account turbulent inertial deposition of aerosol to the walls as well as loss due to gravitational settling. At Cabauw tower, theoretical estimates of the loss in vertical tubing with $10 \mathrm{~mm}$ ID and $200 \mathrm{~m}$ lengths with flow rate of $1.1 \mathrm{~m}^{3} \mathrm{~h}^{-1}$ yielded a total efficiency of $73 \%$, the same value as observed. ${ }^{222} \mathrm{Rn}$ progeny loss increased strongly at activity concentrations below $1 \mathrm{~Bq} \mathrm{~m}^{-3}$. Based on our experiments, an empirical correction function for ${ }^{222} \mathrm{Rn}$ progeny measurements when sampling through long Decabon tubing was developed, allowing correction of respective measurements for this particular experimental setting (tubing type and diameter, flow rate, aerosol size distribution) with an estimated uncertainty of 10-20\% for activity concentrations between 1 and $2 \mathrm{~Bq} \mathrm{~m}^{-3}$ and less than $10 \%$ for activity concentrations above $2 \mathrm{~Bq} \mathrm{~m}^{-3}$.
\end{abstract}

\section{Introduction}

Soil-borne ${ }^{222}$ radon $\left({ }^{222} \mathrm{Rn}\right)$ is widely used as a tracer for atmospheric mixing and transport model validation (e.g. Jacob and Prather, 1990; Taguchi et al., 2011), as its sources are relatively well known (e.g. Nazaroff, 1992; Karstens et al., 2015), while its only sink is radioactive decay. Continuous atmospheric ${ }^{222} \mathrm{Rn}$ is normally measured via the activity of its short-lived progeny, such as ${ }^{218}$ polonium $\left({ }^{218} \mathrm{Po}\right)$ and ${ }^{214}$ polonium $\left({ }^{214} \mathrm{Po}\right)$, which are attached to aerosols shortly after generation in the atmosphere (Porstendörfer, 1994). In so-called two-filter systems, filtered air that only contains ${ }^{222} \mathrm{Rn}$ (with ambient progeny removed) is flushed through a large delay chamber and the new ${ }^{222} \mathrm{Rn}$ progeny produced in situ inside the tank is then collected on a second internal filter where their decay is monitored (e.g. Whittlestone and Zahorowski, 1998; Chambers et al., 2011). Alternative ${ }^{222} \mathrm{Rn}$ monitors, the so-called one-filter systems, collect ${ }^{222} \mathrm{Rn}$ progeny directly from ambient air on a static filter or automatically changing filters and measure its decay rates on the filter. In this style of detector, atmospheric ${ }^{222} \mathrm{Rn}$ activity concentration is then deduced from the filter activity of its progeny, making assumptions about the disequilibrium between ${ }^{222} \mathrm{Rn}$ and its progeny on the filter and in the atmosphere (e.g. Levin et al., 2002; Schmithüsen et al., 2017). Disequilibrium between ${ }^{222} \mathrm{Rn}$ and its daughters depends on height above ground level, on meteorological conditions and on the influence of processes causing aerosol loss by dry or wet deposition (see e.g. Jacobi and André, 1963; Schery and Wasiolek, 1993; Porstendörfer, 1994). These non-negligible 
biases can be investigated by comparison with two-filter detectors (Xia et al., 2010).

In addition, potential artefacts from air intake and sampling lines of one-filter systems need to be investigated before one-filter monitors could be implemented at locations (e.g. at tower stations), where long intake tubing is required. To minimize loss of aerosol-attached ${ }^{222} \mathrm{Rn}$ daughters in the intake systems, one-filter monitors are normally used only at ground level stations, where short intake lines are possible. This principally disqualifies one-filter systems to be applied at tall tower stations, unless the filter head can be installed directly at the level where the ${ }^{222} \mathrm{Rn}$ daughter measurements will be performed (e.g. at an accessible platform). Alternatively, corrections must be applied for loss of aerosolattached ${ }^{218}$ Po or other progeny in the tubing. This, however, requires full quantitative understanding of all aerosol transport loss and deposition processes in the intake system, such as diffusion to the walls, sedimentation or inertial deposition (see e.g. Willeke and Baron, 2005, for a comprehensive discussion of these processes).

In the present work, we present the results from dedicated laboratory and field experiments, which had the aim to determine ${ }^{222} \mathrm{Rn}$ progeny loss in long tubing. The study was motivated by the requirement to accompany greenhouse gases measurements with continuous ${ }^{222} \mathrm{Rn}$ observations within the new European ICOS (Integrated Carbon Observation System) atmospheric station network (https://www.icos-ri.eu/icos-research-infrastructure/ icos-national-networks). Due to space restrictions at many of the ICOS tall tower sites, it may be difficult to host two-filter systems with their huge detector volumes (Whittlestone and Zahorowski, 1998), whereas the Heidelberg static one-filter radon monitor (Levin et al., 2002) requires only little space. The question of compatibility of existing one- and two-filter systems for ${ }^{222} \mathrm{Rn}$ monitoring as well as first estimates of disequilibrium have been addressed in a companion paper (Schmithüsen et al., 2017), where results from a European-wide comparison study are reported. In the current work we address potential ${ }^{222} \mathrm{Rn}$ progeny loss in standard Decabon tubing, as this tubing material is prescribed to be used at the tall tower stations of the ICOS network. From our laboratory experiments, a correction algorithm for ${ }^{222} \mathrm{Rn}$ progeny loss in tubing up to $200 \mathrm{~m}$ length has been developed. Validation of these laboratory experiments with a comparable experimental setting was possible during a measurement campaign at the Cabauw tall tower station in the Netherlands, where atmospheric ${ }^{222} \mathrm{Rn}$ observations are routinely performed with a two-filter monitor (from ANSTO, Whittlestone and Zahorowski, 1998).

\section{Methods}

\subsection{Heidelberg static (one) filter ${ }^{222}$ Rn monitor (HRM)}

In Heidelberg, a medium-sized city located in the Upper Rhine Valley in south-western Germany $\left(49^{\circ} 25^{\prime} \mathrm{N}, 8^{\circ} 41^{\prime} \mathrm{E}\right.$; $116 \mathrm{~m}$ a.s.l.), atmospheric ${ }^{222} \mathrm{Rn}$ daughter activity concentrations have been continuously monitored since 1996 with a static filter system. Measurements were conducted at the Institut für Umweltphysik, Heidelberg University, located on the university campus on the outskirts of the city. Since 1999, ambient air is collected at about $30 \mathrm{~m}$ above local ground. These Heidelberg ${ }^{222} \mathrm{Rn}$ data have been used as a tracer for boundary layer mixing in a number of studies (e.g. Hammer and Levin, 2009; Levin et al., 2011) or for regional transport model comparison exercises (Taguchi et al., 2011).

The principal set-up of the HRM was designed in the 1990s (Levin et al., 2002). The monitor was modernized in 2010 by implementing state-of-the-art electronics as well as data acquisition and evaluation hardware and software (Rosenfeld, 2010). The system consists of a homemade filter holder, carrying a Whatman filter (QMA $\varnothing 47 \mathrm{~mm}$ ), where all aerosols from an ambient airflow of ca. $1 \mathrm{~m}^{3} \mathrm{~h}^{-1}$ (measured with a Bronkhorst mass flow meter, model F-112ACAAD-22-V) are actively deposited. A surface barrier detector (Canberra CAM $900 \mathrm{~mm}^{2}$ active surface) mounted in the filter holder at about $5 \mathrm{~mm}$ distance from the loaded filter surface measures the $\alpha$ particles from the decaying ${ }^{222} \mathrm{Rn}$ and ${ }^{220} \mathrm{Rn}$ daughters. Hourly or half-hourly integrated $\alpha$ spectra are stored for later separation of ${ }^{214}$ polonium $\left({ }^{214} \mathrm{Po}\right)$ counts from the spectrum. Levin et al. (2002) explain evaluation of the spectra in detail. Taking into account the airflow rate through the filter, the filter efficiency (assumed as 100\%) and the solid angle of the detector, which depends on the distance of the detector from the filter, finally allow estimation of the atmospheric ${ }^{214} \mathrm{Po}$ activity concentration. For calculation of ambient ${ }^{222} \mathrm{Rn}$ activity concentration, a correction for disequilibrium of ${ }^{214}$ Po has to be made (Levin et al., 2002; Schmithüsen et al., 2017).

\subsection{Set-up of the line tests at the Heidelberg measurement site}

To minimize aerosol loss in the sample intake, the standard intake line for the HRM is a ca. $0.5 \mathrm{~m}$ long $8 \mathrm{~mm}$ inner diameter (ID) Teflon tubing. In Heidelberg, this tubing is connected directly to outside air through a hole in the laboratory window. For investigating the effect of different intake lines on the measured ${ }^{214}$ Po activity concentration, we used standard Decabon (SertoFlex) tubing with $12 \mathrm{~mm}$ outer and $8.2 \mathrm{~mm}$ inner diameter, which was varied in length between 16 and $200 \mathrm{~m}$. Before each test, the monitor with the long intake tube was run with a standard intake line for more than 1 week in parallel to our routine Heidelberg radon monitor. This allowed us to determine a "calibration" of the so-called 
line test monitor (LTM) relative to the Heidelberg routine instrument (HD-R). Small systematic differences of typically less than $5 \%$ can occur between monitors, which may be due to slightly different solid angles or efficiencies of the surface barrier detectors or of the mass flow meter calibrations. From this comparison we estimate a statistical measurement uncertainty of activity ratios for the two Heidelberg monitors of about $25 \%$ for ambient activity concentrations below $1 \mathrm{~Bq} \mathrm{~m}^{-3}$ and of $10 \%$ or less for concentrations above $1 \mathrm{~Bq} \mathrm{~m}^{-3}$ After the initial calibration period, each line test was run for at least 3 weeks to make sure that the typical activity concentration range in Heidelberg of $1-15 \mathrm{~Bq} \mathrm{~m}^{-3}$ was covered by the measurements. For these laboratory tests, the extended intake lines were rolled up to a diameter of approximately $0.5 \mathrm{~m}$; they were always kept horizontally and at laboratory temperature of $19-22^{\circ} \mathrm{C}$. For all laboratory tests with line lengths $>100 \mathrm{~m}$, flow rates were around $1 \mathrm{~m}^{3} \mathrm{~h}^{-1}$ $( \pm 10 \%)$, keeping the contact time per length of tubing constant within about $10 \%$. For the tests with shorter tubing, flow rates were up to $70 \%$ higher.

\subsection{Set-up of the Cabauw experiment $\left(\mathrm{NL}, 5^{\circ} 58^{\prime} \mathrm{N}\right.$ $4^{\circ} 56^{\prime} \mathrm{E} ;-0.7 \mathrm{~m}$ a.s.l.)}

Cabauw tower is a $213 \mathrm{~m}$ high tower, specifically built for meteorological research to establish relations between the states of the atmospheric boundary layer, land surface conditions and the general weather situation for all seasons. Cabauw tower is located in the western part of the Netherlands in a polder $0.7 \mathrm{~m}$ below average sea level. The North Sea is more than $50 \mathrm{~km}$ away to the WNW.

${ }^{222} \mathrm{Rn}$ is continuously measured at Cabauw station from two different heights, 20 and $200 \mathrm{~m}$ above ground level; air is drawn at approximately $100 \mathrm{~L} \mathrm{~min}^{-1}$ through $7 \mathrm{~cm}$ outer diameter terylene fibre water pipes through stack blowers into the measurement devices. These ANSTO radon monitoring devices are based on the two-filter technique (Whittlestone and Zahorowski, 1998; Zahorowski et al., 2004). The details of the Cabauw monitors and their calibration are described in Popa et al. (2011) as well as in the companion paper by Schmithüsen et al. (2017).

Our first set of measurements with a HRM at Cabauw tower (15 December 2011 to 21 February 2012) was through a pre-installed Decabon tubing (in total $200 \mathrm{~m}$ ) from the $180 \mathrm{~m}$ level down to the basement, where the HRM filter head was installed. This tubing had a slightly larger inner diameter than the tubing tested in the laboratory, namely $10 \mathrm{~mm}$, and the flow rate was $1.1 \mathrm{~m}^{3} \mathrm{~h}^{-1}( \pm 10 \%)$. A second set of measurements was performed with the HRM standard intake line $(0.5 \mathrm{~m})$ also from the $180 \mathrm{~m}$ platform (10 July26 August 2012). For these latter measurements we assume no aerosol loss during air intake of the HRM; the respective data thus serve as reference for the compatibility of the two measurement systems (ANSTO and HRM) located at slightly different heights above ground (ANSTO: $200 \mathrm{~m}$ and HRM: $180 \mathrm{~m}$ ). They allow the determination of possible combined calibration biases or mean differences due to disequilibrium of the HRM-measured ${ }^{214}$ Po to the ANSTOmeasured ${ }^{222} \mathrm{Rn}$ activity concentrations (see accompanying paper by Schmithüsen et al., 2017).

\section{Results}

\subsection{Results of the line tests performed in Heidelberg}

Figure 1 shows an example of results from a line test with $8.2 \mathrm{~mm}$ inner diameter Decabon tubing in the Heidelberg laboratory. Here we plot the ${ }^{214}$ Po activity concentration measured on ambient air collected via a $200 \mathrm{~m}$ intake line (LTM) vs. that measured with the HD-R monitor sampling the same air via a $0.5 \mathrm{~m}$ intake tubing. The correlation between the two data sets is very good; however, the slope of the regression line is only 0.66 , indicating that we lose more than $30 \%$ of ${ }^{222} \mathrm{Rn}$ progeny activity concentration in the tubing. When plotting the ratio of the respective data vs. the activity measured with the LTM we can further see that at activity concentrations smaller than $\approx 2 \mathrm{~Bq} \mathrm{~m}^{-3}$, the relative activity loss for the LTM appears to be even larger than at high activities. Line tests with shorter tubing than $200 \mathrm{~m}$ show a similar pattern; however, the shorter the tubing is, the higher the "saturation ratio" $R$ at high atmospheric activity concentrations. The activity dependency of the ratios LTM/HD-R (e.g. Fig. 1b) can be approximated by a saturation curve according to the following function:

$\frac{c_{\mathrm{LTM}}}{c_{\mathrm{HD}-\mathrm{R}}}=R(L)-A \cdot \exp ^{-\frac{c_{\mathrm{LTM}}}{c_{0}}}$,

where the free parameters $A$ and $C_{0}$ are constants, and $R(L)$ is the "saturation" activity ratio for line length $L$. The activity ratios from the $200 \mathrm{~m}$ line test have been fitted accordingly in Fig. $1 \mathrm{~b}$ with the fit curve plotted as solid red line with $R(L)=0.66$. Similar fit curves as shown in Fig. 1 have been calculated through all laboratory line test results with tubing between 16 and $200 \mathrm{~m}$. This process yielded saturation ratios $R(L)$ decreasing with increasing line length $L$; respective results are displayed in Fig. 2a (red squares), where the saturation ratios $R(L)$ are plotted vs. the length of the tubing of the LTM. An exponentially decreasing saturation value $R(L)$ is observed with increasing length $L$ of the tubing and a respective exponential fit is plotted through the data (solid red line in Fig. 2a):

$R(L)=\exp ^{-\frac{L}{L_{0}}}$,

where $L_{0}$ is a constant parameter. Note that a straight line would fit our data equally well, but we expect $R(L)$ to approach zero at infinite line length; therefore we used an exponential fit. The error bars in Fig. 2a correspond to the standard deviation of all measurements from each line test 

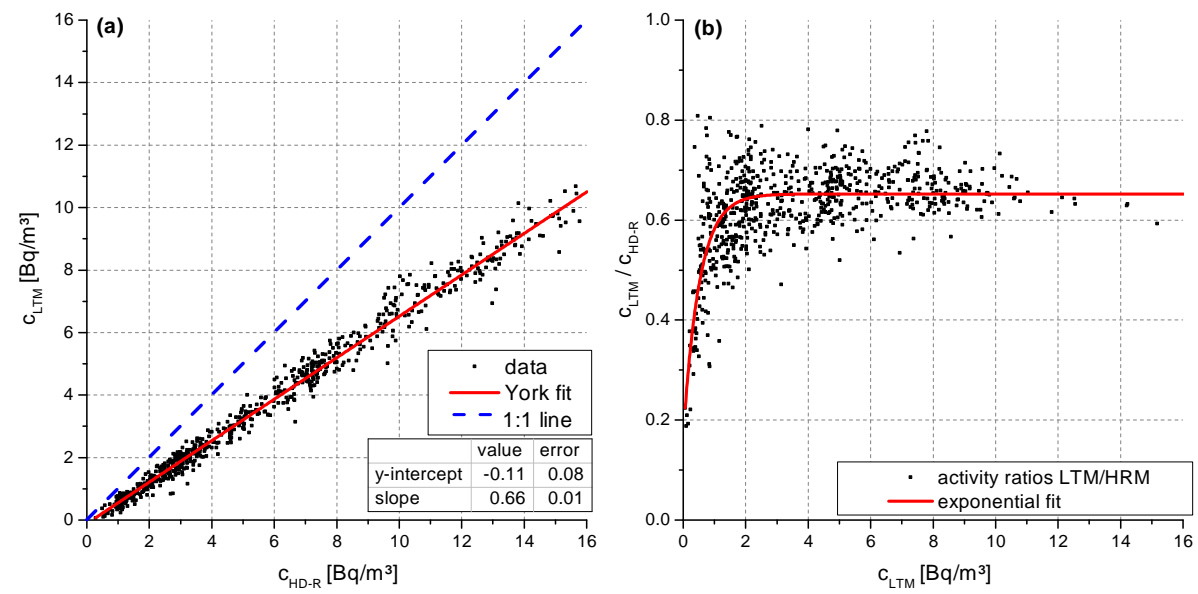

Figure 1. (a) Correlation of the ${ }^{214}$ Po activity concentration measured with the line test monitor (LTM) sampling via a $200 \mathrm{~m}$ intake line vs. that measured with the Heidelberg routine monitor (HD-R). The red line is a least squares fit (York et al., 2004) through the data yielding a slope of 0.66 ; the dashed blue line shows the $1: 1$ relation. (b) Activity concentration ratio of the LTM and the HD-R monitor plotted vs. the activity concentration measured with the LTM. The red line is an exponential fit through the data according to Eq. (1).

(a)

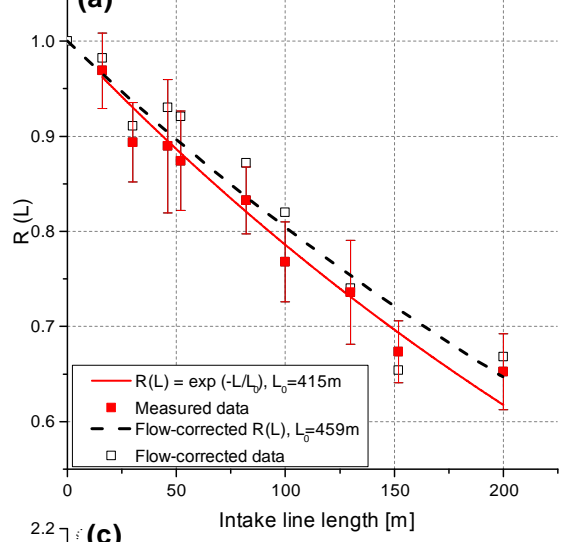

(c)

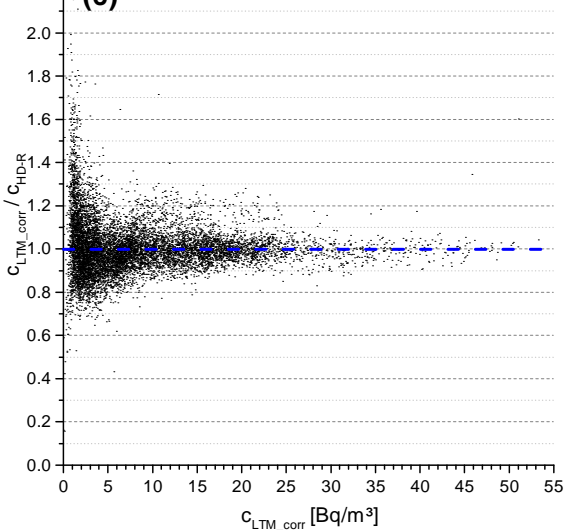

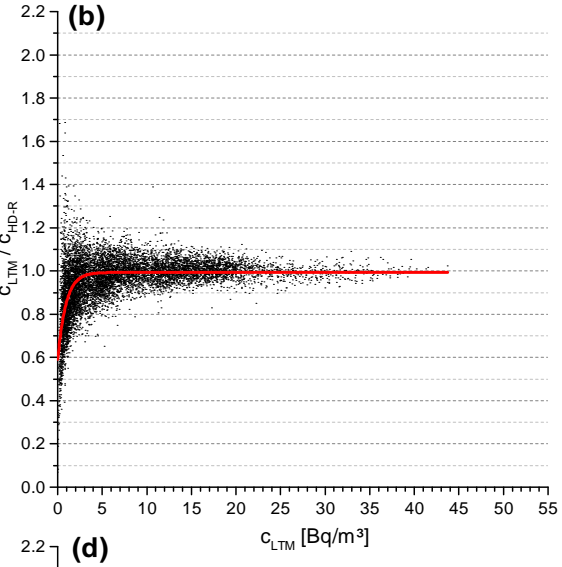

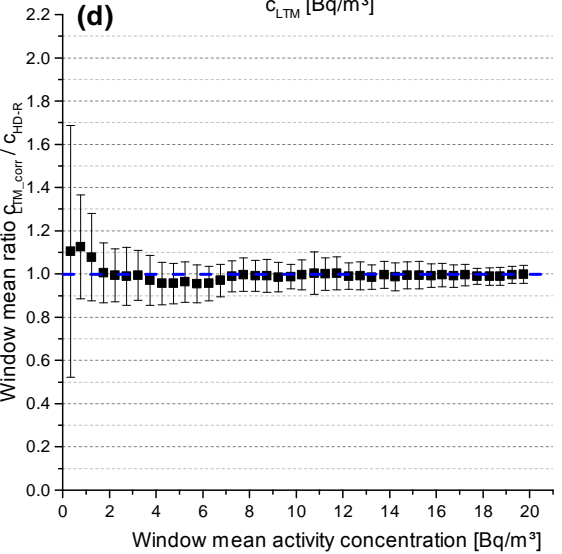

Figure 2. (a) Length-dependent saturation values as determined from individual line tests (compare also Figs. S1-S9 in the Supplement). The solid red line is an exponential fit calculated through all experimental data according to Eq. (2). Black open symbols show experimental values adjusted to a standard flow rate of $1 \mathrm{~m}^{3} \mathrm{~h}^{-1}$, according to Eqs. (3)-(5), with the dashed black line being the exponential fit through these adjusted data. (b) Length-corrected line test results (i.e. normalized to $R=1$ ) together with the saturation fit curve calculated according to Eq. (1). (c) Activity concentration ratio of corrected LTM data and HD-R data without tubing. Panel (d) gives the standard deviations of ratios displayed in (c) binned into $0.5 \mathrm{~Bq} \mathrm{~m}^{-3}$ ranges. 
with activity concentrations $>7 \mathrm{~Bq} \mathrm{~m}^{-3}$. Equation (2) could therefore in principle be used to correct measurements for the loss of ${ }^{222} \mathrm{Rn}$ progeny activity concentration at activity concentrations $>7 \mathrm{~Bq} \mathrm{~m}^{-3}$ in $8.2 \mathrm{~mm}$ Decabon tubing.

In order to additionally account for the activity-dependent loss (i.e. at activity values $<\approx 7 \mathrm{~Bq} \mathrm{~m}^{-3}$ ), we corrected all our line test data with different line lengths for the general "saturation" loss by dividing all values by their respective saturation value $R(L)$ and combined them into one single "normalized" data set of corrected activity ratios (Fig. 2b). We then applied a joint fit through all data according to Eq. (1). This fit using the length-corrected data - by definition - yields a mean saturation value $R=1$. The maximum activity concentration loss at very low activities $\left(c_{\text {LTM }} \rightarrow 0\right)$ approaches $40 \%$ (Fig. 2b). The parameters of the joint fit as well as those of the fit for the general length-dependent loss correction (as shown in Fig. 2a) are $L_{0}=415 \mathrm{~m} ; A=0.41$; $c_{0}=0.92 \mathrm{~Bq} \mathrm{~m}^{-3}$.

\subsection{Evaluation of the empirical activity loss correction}

In order to test if our empirical correction method yields reliable results, we have applied Eqs. (1) and (2), using the fit parameters from Fig. 2 to all individual line tests and plotted the results in Figs. S1-S9 in the Supplement. These figures show in their upper left panels the original $c_{\mathrm{LTM}} / c_{\mathrm{HD}-\mathrm{R}}$ ratios, in their lower left panels the ratios $c_{\mathrm{LTM}} / c_{\mathrm{HD}-\mathrm{R}}$ of the LTM-corrected data, in their upper right panels the linear correlation of corrected $c_{\mathrm{LTM}}$ with $c_{\mathrm{HD}-\mathrm{R}}$ and in their lower right panels the regular residuum from the fit line in the lower left panel. For all line lengths the slopes lie between 0.997 and 1.064 and the scatter of the corrected ratios for activities $>2 \mathrm{~Bq} \mathrm{~m}^{-3}$ is less than $20 \%$ in all cases, but with tubing longer than $50 \mathrm{~m}$ it may increase to more than $50 \%$ for activity concentrations lower than $1 \mathrm{~Bq} \mathrm{~m}^{-3}$. For a quantitative estimate of the average uncertainty of our correction of the laboratory results, we display in Fig. $2 \mathrm{c}$ the ratios between normalized and corrected LTM data and the routine HRM data. In Fig. 2d, we calculated standard deviations for binned activity concentration ranges of $0.5 \mathrm{~Bq} \mathrm{~m}^{-3}$ each. The standard deviation is of order $60 \%$ for the lowest activity concentration range of $0-0.5 \mathrm{~Bq} \mathrm{~m}^{-3}$, but it quickly decreases to less than $20 \%$ above $1 \mathrm{~Bq} \mathrm{~m}^{-3}$. Taking into account the uncertainty of activity ratios from two HRMs without tubing of ca. $25 \%$ below $1 \mathrm{~Bq} \mathrm{~m}^{-3}$ (see Sect. 2.2) and about $10 \%$ above $1 \mathrm{~Bq} \mathrm{~m}^{-3}$, the additional uncertainty of the correction for the effects of long tubing is of the order of $40 \%$ below $1 \mathrm{~Bq} \mathrm{~m}^{-3}$, decreases to about $17 \%$ for $1.5 \mathrm{~Bq} \mathrm{~m}^{-3}$ and to less than $10 \%$ above $2 \mathrm{~Bq} \mathrm{~m}^{-3}$. We find a small bias in the corrected mean ratios of ca. $10 \%$ below $1.5 \mathrm{~Bq} \mathrm{~m}^{-3}$. A more sophisticated correction may allow for adjusting for that bias; however, we decided to keep the correction simple and valid for all tube lengths. In view of the relatively large statistical uncertainty of the measurement through long tubing $(>50 \mathrm{~m})$ at activity concentrations below $1.5 \mathrm{~Bq} \mathrm{~m}^{-3}$ and in view of the fact that we cannot fully transfer our laboratory experiments to real field measurements (see below), we refrain here from further second-order adjustments.

\section{3 $\quad{ }^{222} \mathrm{Rn}$ progeny loss during ambient air sampling at Cabauw}

In addition to the line tests made with rolled-up $8.2 \mathrm{~mm}$ ID Decabon tubing in the Heidelberg laboratory and to evaluate the potential correction for radon progeny loss in vertical tubing, a line test has been made during the comparison campaign at Cabauw (Schmithüsen et al., 2017). From a direct comparison between the local ANSTO system, measuring ${ }^{222} \mathrm{Rn}$ at $200 \mathrm{~m}$ and the HRM, sampling air through a $0.5 \mathrm{~m}$ tubing at the $180 \mathrm{~m}$ platform, we obtained a mean difference between the ANSTO ${ }^{222} \mathrm{Rn}$ data and the HRM ${ }^{214} \mathrm{Po}$ data of ANSTO $/ \mathrm{HRM}=1.11$. The $11 \%$ bias between the two systems may be due to calibration and/or disequilibrium differences between the two systems but is, most probably, due to calibration differences (Schmithüsen et al., 2017). For the line test we sampled air for the HRM over 2 months through $200 \mathrm{~m}$ and $10 \mathrm{~mm}$ ID Decabon tubing from the $180 \mathrm{~m}$ level of the Cabauw tower at a flow rate of $1.1 \mathrm{~m}^{3} \mathrm{~h}^{-1}( \pm 10 \%)$, while the routine ANSTO instrumentation was also measuring ${ }^{222} \mathrm{Rn}$ in air collected at $200 \mathrm{~m}$. In the comparison shown in Fig. 3, we have corrected the ANSTO data with the above mentioned calibration factor of $1 / 1.11$, but there is still a significant difference visible between the two data sets. The slope of the regression line shown in Fig. $3 \mathrm{~b}$ is HRM/ANSTO_corr $=0.73$, indicating a mean loss of $27 \%$ of aerosol-bound ${ }^{222} \mathrm{Rn}$ progeny in the $200 \mathrm{~m}$ tubing of the HRM. From our laboratory tests we would have expected a larger loss, i.e. $34 \%$ for a $200 \mathrm{~m}$ tubing. Note, however, that a tubing with slightly smaller inner diameter of $8.2 \mathrm{~mm}$ was used in the laboratory tests, while at Cabauw tower the tubing had an inner diameter of $10 \mathrm{~mm}$, which can explain most of the difference. Moreover, in the laboratory tests the tubing was rolled up and lying on the floor, with potential loss due to inertial deposition on the bent tube walls as well as gravitational settling of aerosol and associated loss (see Sect. 4).

\section{Discussion}

The relative loss of ${ }^{214}$ Po activity concentrations (see Eq. 2: $\left.R(L)=A_{\text {line }} / A_{\text {direct }}\right)$ when sampling through a long tubing shows the expected correlation with tubing length $L$ (assumed here to be exponential, but a linear correlation would also fit the measurement data) and a rather subtle dependency on the atmospheric activity concentration itself (Fig. 2b). Intake lines are known to be a potential sink for aerosols (see e.g. Willeke and Baron, 2005; von der Weiden et al., 2009), and the majority of radon daughters measured with the onefilter HRM are attached to aerosols. The exact dependency of $R(L)$ on the intake line length depends on the size of 
the aerosols carrying the radon daughter activity and on the flow regime in the tubing as well as its shape and orientation. Reineking et al. (1988) and Porstendörfer et al. (1994) report that most radon progeny activity in open air is carried by particles in the accumulation mode, with an average median aerodynamic diameter of $369 \mathrm{~nm}$ (range of $173-645 \mathrm{~nm}$ ). Depending on meteorological conditions, a small fraction could also be found in the nucleation mode, with a diameter size range of 10-100 nm (Reineking et al., 1988). The flow regime in our Decabon tubing with $d=8.2$ or $10 \mathrm{~mm}$ ID, a flow rate $Q$ of about $1 \mathrm{~m}^{3} \mathrm{~h}^{-1}$ and air (and particle) velocities between $3.5<U<5.3 \mathrm{~m} \mathrm{~s}^{-1}$ cannot be characterized as purely laminar (Reynolds number $R e<2000$ ) or as purely turbulent $(\operatorname{Re}>4000)$. With $R e=U \cdot d / v$, where $v$ is the kinematic viscosity of the medium (in our case air at approximately $20^{\circ} \mathrm{C}$, i.e. $v=1.5 \times 10^{-5} \mathrm{~m}^{2} \mathrm{~s}^{-1}$ ), our Reynold numbers lie between 2350 and 2900, i.e. in the transitional regime, where for many loss processes no formula is available (von der Weiden et al., 2009).

For the laboratory experiment, four transport loss processes are potentially relevant to explain the observed radon progeny loss: (1) diffusion by Brownian motion towards the walls; (2) turbulent inertial deposition, when the (larger) particles cannot follow turbulent streamlines and thus stick to the walls; (3) gravitational settling in the horizontal tube; and (4) inertial deposition on the bent tube walls. For the Cabauw experiment, with vertical tubing over most of the intake line, only the first two processes are potentially of relevance.

1. Loss by molecular diffusion following a gradient towards the walls is stated by von der Weiden et al. (2009) as being relevant only for very small particles ( $<100 \mathrm{~nm}$ aerodynamic diameter). With aerodynamic diameters between 173 and $645 \mathrm{~nm}$, this process is probably negligible for the Heidelberg lab experiments and at Cabauw tower, too. However, if a significant fraction of radon progeny would be unattached, this loss process may be significant (see below).

2. Although our flow is in the transitional regime between laminar and turbulent, loss through turbulent inertial deposition may still be relevant. Von der Weiden et al. (2009) give an equation to estimate the turbulent inertial deposition efficiency (their Eq. 28), based on an experimentally determined turbulent inertial deposition velocity $V_{\mathrm{t}}$ (Eq. 29) in tubing of length $L$ with diameter $d$

$$
\eta_{\text {turb,inert }}=\exp \left(-\frac{\pi \cdot d \cdot L \cdot V_{\mathrm{t}}}{Q}\right)
$$

$V_{\mathrm{t}}$ can be estimated with Eq. (29) of von der Weiden et al. (2009), based on the Stokes number Stk and the
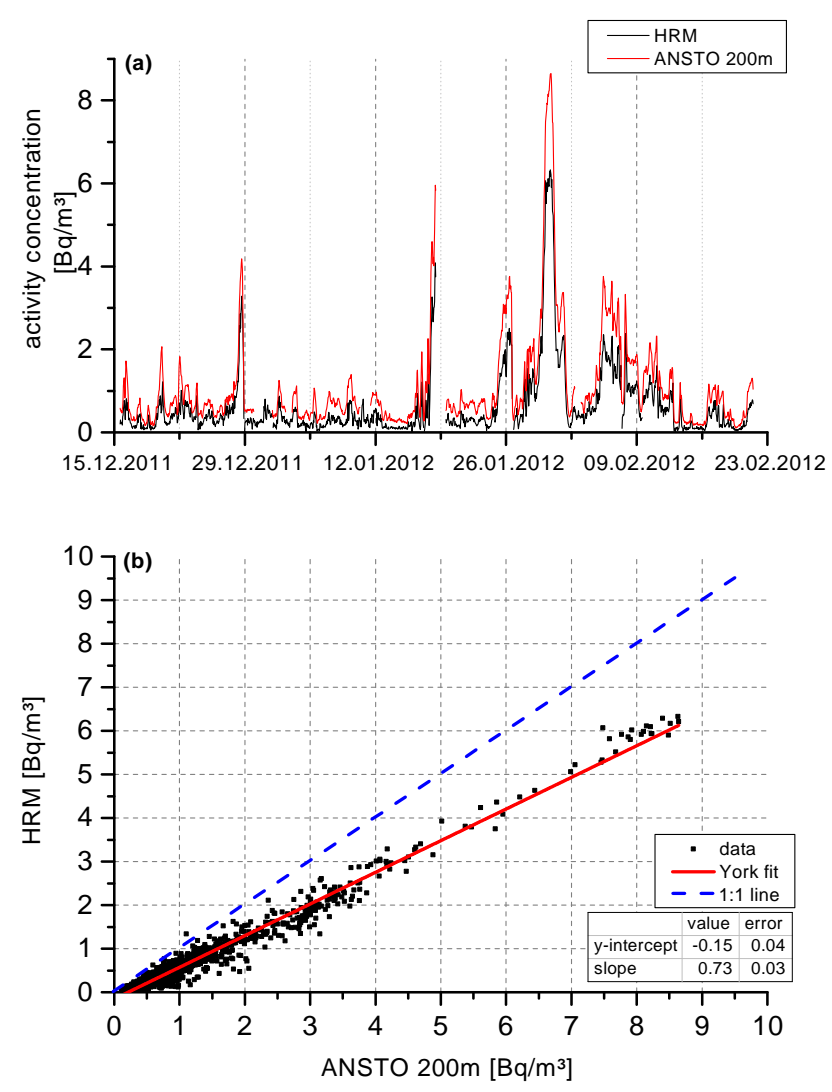

Figure 3. Results from the line test experiment at Cabauw tower. (a) shows ${ }^{222} \mathrm{Rn}$ activity concentrations measured with the ANSTO system on air collected from the $200 \mathrm{~m}$ platform (red line), but corrected by a factor of $1 / 1.11$ (see text) in comparison to the HRM ${ }^{214}$ Po measurements on air from the $180 \mathrm{~m}$ level of the tower collected through a $200 \mathrm{~m}$ Decabon tubing (black line). (b) shows the scatter plot of the two records with a geometric mean regression line (York et al., 2004) yielding a slope of 0.73 .

Reynolds $R e$ number according to

$$
\begin{aligned}
& V_{\mathrm{t}}= \\
& \frac{\left[6 \times 10^{-4}\left(0.0395 \cdot S t k \cdot R e^{3 / 4}\right)^{2}+2 \times 10^{-8} \cdot R e\right] \cdot U}{5.03 \cdot R e^{1 / 8}} .
\end{aligned}
$$

The Stokes number is calculated according to Brockmann $\left(2005\right.$, his Eqs. 6-1 and 6-2) $S t k=V_{\mathrm{ts}} \cdot U /(d \cdot g)$, where $V_{\mathrm{ts}}$ is the gravitational settling velocity (in our case of aerosol with $369 \mathrm{~nm}$ median aerodynamic diameter estimated to about $2 \mathrm{~cm} \mathrm{~h}^{-1}$; Seinfeld and Pandis, 2006), and $g$ is the gravitational acceleration. With a Stokes number of $3.6 \times 10^{-4}$ for the lab experiments, Eq. (3) yields a transport efficiency of $\eta_{\text {turb,inert }}=0.66$. For the Cabauw tower tubing of $10 \mathrm{~mm}$ ID and flow rate of $1.1 \mathrm{~m}^{3} \mathrm{~h}^{-1}$ the Stokes number is smaller; i.e. $2.2 \times 10^{-4}$ and the aerosol loss by turbulent deposition is also smaller and estimated by Eqs. (3) and (4) to $\eta_{\text {turb,inert }}=0.73$. 
3. In the laboratory tests, loss may also have been due to gravitational settling in the rolled-up tubes kept horizontally, although this effect is more important for larger particles $>500 \mathrm{~nm}$ (von der Weiden et al., 2009). We can estimate the respective loss for laminar flow according to Eq. (24) of von der Weiden et al. (2009):

$$
\begin{aligned}
\eta_{\text {tube,grav }}= & 1-\frac{2}{\pi} \cdot\left(2 \varepsilon \cdot \sqrt{1-\varepsilon^{2 / 3}}-\varepsilon^{1 / 3}\right. \\
& \left.\cdot \sqrt{1-\varepsilon^{2 / 3}}+\arcsin \left(\varepsilon^{1 / 3}\right)\right),
\end{aligned}
$$

where $\varepsilon=3 / 4 \cdot Z$ and $Z=L \cdot V_{\mathrm{ts}} /(U \cdot d)$. For turbulent flow von der Weiden et al. (2009) give a different equation, i.e. their Eq. (26) (Eq. 6-40 in Brockmann, 2005):

$\eta_{\text {tube,grav }}=\exp \left(-\frac{d \cdot L \cdot V_{\mathrm{ts}}}{Q}\right)$.

However, for a settling velocity $V_{\mathrm{ts}} \approx 2 \mathrm{~cm} \mathrm{~h}^{-1}$ (as estimated for our median diameter aerosol of $369 \mathrm{~nm}$, see above) both Eq. (5a) and (5b) yield the same loss, i.e. for a $200 \mathrm{~m}$ horizontal tube of $d=8.2 \mathrm{~mm} \mathrm{ID}$, a loss of about $3 \%$. Loss due to gravitational settling would double for a $645 \mathrm{~nm}$ median diameter aerosol and be only about $1 \%$ for $175 \mathrm{~nm}$ aerosol.

4. The fourth process to be considered for loss in the laboratory experiment is due to inertial deposition at the walls of the bent tubing. Calculations of this lost process are commonly made following the data-based empirical correction functions given by Pui et al. (1987) (see e.g. Brockmann, 2005, and Von der Weiden et al., 2009). For laminar flow, Pui et al. (1987) show in their Figs. 7 and 8 that aerosol loss in bent tubing is negligible for Stokes numbers smaller than 0.01 , which is the case in our laboratory experiments (see above). For turbulent flow, the latter authors developed a correction function independent of the Reynolds number and the curvature of the bend, i.e.

$\eta_{\text {bend,inert }}=\exp (-2.823 S t k \cdot \phi)$,

where $\phi$ is the angle of the bend in radians and Stk is the Stokes number. Although the Stokes number in our experimental set-up for aerosol with median aerodynamic diameter of about $370 \mathrm{~nm}\left(V_{\mathrm{ts}} \approx 2 \mathrm{~cm} \mathrm{~h}^{-1}\right)$ is small (ca. $\left.3.6 \times 10^{-4}\right)$, in the laboratory experiments with up to $200 \mathrm{~m}$ tubing rolled up, $\phi$ gets very large. With Eq. (6) we would thus obtain an efficiency of $\eta_{\text {bend,inert }}=0.45$, only for this loss process. The data set used by Pui et al. (1987) to establish Eq. (6) had, however, Re numbers of 6000 and 10000 , and a curvature ratio $R_{0}$ (i.e. the radius of the bend divided by the radius of the tube, Brockmann, 2005) of $\sim 6$. Thus flow and bending conditions under which Eq. (6) was obtained were quite a lot more turbulent and more sharply bent, respectively, compared to the conditions encountered within our experiment $\left(R e=2900\right.$ and $\left.R_{0}=61\right)$. However, Pui et al. (1987) affirm the insignificance of $R_{0}$ in Eq. (6) only for a range of $5 \leq R_{0} \leq 30$. Considering this, we have to conclude that the conditions of our experiment might be only partially or not at all suitable to be evaluated with Eq. (6), leaving a quantitative estimate of this loss process open. Therefore, although we cannot fully rule out in our laboratory experiments aerosol loss due to inertial deposition in the bent tubing, it is likely that this effect is only small. One strong argument for this assumption is that we would have observed much larger differences in aerosol loss between laboratory experiments (with the rolled-up tubing) and the field experiment at Cabauw tower, where ${ }^{222} \mathrm{Rn}$ progeny was sampled through an almost straight vertical tubing.

In conclusion, we assume that the most relevant process for aerosol loss in both our experimental settings was most probably through turbulent inertial deposition on the walls of the tubing. We favour this loss process also because, contrary to the other loss processes, it does not depend much on the median aerodynamic diameter of the aerosol. In fact, we cannot expect the size distributions of the ${ }^{222} \mathrm{Rn}$ daughtercarrying aerosol to be identical at Cabauw tower located close to the sea and in Heidelberg, a rather polluted and more continental station. A few percent of loss may have additionally occurred through gravitational settling in the laboratory experiments. As we used higher flow rates in the laboratory for the shorter line lengths and as aerosol loss in the tubing depends on the flow rate (see Eqs. 3-5), we made an attempt to correct the laboratory results by normalising them all to a flow rate of $1 \mathrm{~m}^{3} \mathrm{~h}^{-1}$ (see open squares in Fig. 2a). This yielded slightly higher values for the shorter line lengths and an exponential fit with a slightly smaller decrease rate with length $L$. The difference to the original fit curve through the uncorrected experimental data increases with line lengths to $4.5 \%$ for a $200 \mathrm{~m}$ tubing, which is well within the uncertainty of our measurements.

The activity dependency of aerosol loss, which was found in the laboratory (see Fig. 2b) as well as in the field experiment at Cabauw (not shown), is more difficult to explain. One hypothesis is that at low activity concentration also the aerosol concentration is lower, with a potentially shifted size distribution of the progeny-carrying aerosol towards smaller aerodynamic diameters. A significant fraction of progeny may also be unattached during these clean situations (Schery and Wasiolek, 1993). Small particles have a higher diffusion coefficient than the median diameter aerosol and have thus a higher probability to be lost by Brownian diffusion to the walls of the tubing. An even larger loss may be expected for charged (unattached) progeny. A more sophisticated loss calculation would, however, be required to explain the behaviour of progeny loss during these circumstances. This is 
outside the scope of our study, which was only looking for semi-quantitative explanations of our experimental findings.

\section{Conclusions}

Our laboratory and field experiments provided first results on ${ }^{222} \mathrm{Rn}$ progeny loss in long Decabon tubing of 8.2 and $10 \mathrm{~mm}$ ID. As a likely loss mechanism we identified turbulent inertial deposition on the walls of the tubing, because the theoretical estimates of this loss process would equally well explain our findings in the two different experimental settings, i.e. in the laboratory with horizontally kept rolled-up $8.2 \mathrm{~mm}$ ID tubing and in the field with $10 \mathrm{~mm}$ ID straight vertical tubing. In these two cases with flow rates of $1-1.1 \mathrm{~m}^{3} \mathrm{~h}^{-1}$, we estimate sampling efficiencies for $200 \mathrm{~m}$ long tubing between 0.66 (8.2 mm ID) and 0.73 (10 mm ID). When also considering additional loss due to gravitational settling for the rolled-up tubing kept horizontally in the laboratory, the total sampling efficiency is reduced to 0.64 . These theoretical estimates are in surprisingly good agreement with our experimental data that yielded efficiencies of 0.66 for the rolled-up tubing in the laboratory and 0.73 at the Cabauw tower.

Based on this agreement, the correction function, which was empirically derived from our laboratory experiments, showing an exponential increase of loss with tube length seems adequate and applicable for real field measurements with similar tubing and flow rates. One may consider taking a theoretical approach (Eqs. 3 and 4) to correct for ${ }^{222} \mathrm{Rn}$ progeny loss in the tubing. However, we do not recommend this approach as our theoretical estimates were too simplified to be transferred to other tubing and flow conditions.

The observed activity dependency of the loss, when sampling through long tubing, could possibly be explained by decreasing aerodynamic diameter of the radon progenycarrying aerosol. In order to correct for this effect we suggest applying our empirical observation-based function given by Eq. (1). However, one should keep in mind that the uncertainty of this correction is strongly increasing with decreasing atmospheric activity concentration. An additional uncertainty of $10-20 \%$ will be associated with the corrected data, if ${ }^{214}$ Po activity concentrations lie between 1 and $2 \mathrm{~Bq} \mathrm{~m}^{-3}$. For activity concentrations above $2 \mathrm{~Bq} \mathrm{~m}^{-3}$, the additional uncertainty of the correction is smaller than $5 \%$, which seems acceptable in view of other uncertainties associated with the ${ }^{222} \mathrm{Rn}$ progeny measurement. However, for activity concentrations below $1 \mathrm{~Bq} \mathrm{~m}^{-3}$, which very often occur at coastal stations or at sites not too far from the sea, like Cabauw (see Fig. 3), ${ }^{222} \mathrm{Rn}$ progeny sampling through long tubing (i.e. longer than $50 \mathrm{~m}$ ) is not recommended. Here our proposed correction will have huge uncertainty $(>50 \%$, see also figures in the Supplement). For more continental stations, i.e. more than a few hundred kilometres from the coastline, ${ }^{222} \mathrm{Rn}$ activity concentrations drop below $1 \mathrm{~Bq} \mathrm{~m}^{-3}$ only during intensive vertical mixing during summer days or when the air masses have stayed over the continent for less than a day and the continental ${ }^{222} \mathrm{Rn}$ accumulation is still low. Therefore, at these stations one may well accept additional statistical uncertainty due to line loss corrections, also of order $10 \%$, which would be in the same range as the uncertainty of disequilibrium between ${ }^{222} \mathrm{Rn}$ and its measured progeny (see accompanying paper by Schmithüsen et al., 2017).

Data availability. Data tables are going to be published from the University of Heidelberg online at: http://www.iup.uni-heidelberg. de/institut/forschung/groups/kk/Data_html.

\section{The Supplement related to this article is available online at doi:10.5194/amt-10-1313-2017-supplement.}

Acknowledgements. The research leading to these results has received funding from the European Community's Seventh Framework Program (FP7/2007-2013) in the InGOS project under grant agreement no. 284274. We wish to thank the technicians at Cabauw station, Pim van den Bulk and Mark Blom, for their support during the comparison study and Susanne Preunkert, LGGE, Grenoble for helpful discussions. Two anonymous reviewers are gratefully acknowledged for their insightful comments, which helped to improve the manuscript. We acknowledge financial support by Deutsche Forschungsgemeinschaft and Ruprecht-Karls-Universität Heidelberg within the funding programme Open Access Publishing.

Edited by: C. Brümmer

Reviewed by: two anonymous referees

\section{References}

Brockmann, J. E.: Sampling and transport of aerosols, in: Aerosol Measurement - Principles, Techniques, and Applications, edited by: Willeke, K. and Baron, P. A., Van Nostrand Reinhold, New York, 77-111, 2005.

Chambers, S., Williams, A. G., Zahorowski, W., Griffiths, A. D., and Crawford, J.: Separating remote fetch and local mixing influences on vertical radon measurements in the lower atmosphere, Tellus, 63, 843-859, 2011.

Hammer, S. and Levin, I.: Seasonal variation of molecular hydrogen uptake by soils inferred from atmospheric observations in Heidelberg, south-west Germany, Tellus B, 61, 556-565, doi:10.1111/j.1600-0889.2009.00417.x, 2009.

Jacob, D. J. and Prather, M. J.: Radon-222 as a test of convective transport in a general circulation model, Tellus B, 42, 118-134, 1990.

Jacobi, W. and André, K.: The Vertical Distribution of Radon 222, Radon 220 and their decay products in the atmosphere, J. Geophys. Res., 68, 3799-3814, 1963.

Karstens, U., Schwingshackl, C., Schmithüsen, D., and Levin, I.: A process-based ${ }^{222}$ radon flux map for Europe and its compari- 
son to long-term observations, Atmos. Chem. Phys., 15, 1284512865, doi:10.5194/acp-15-12845-2015, 2015.

Levin, I., Born, M., Cuntz, M., Langendörfer, U., Mantsch, S., Naegler, T., Schmidt, M., Varlagin, A., Verclas, S., and Wagenbach, D.: Observations of atmospheric variability and soil exhalation rate of Radon-222 at a Russian forest site: Technical approach and deployment for boundary layer studies, Tellus B, 54, 462$475,2002$.

Levin, I., Hammer, S., Eichelmann, E., and Vogel, F.: Verification of greenhouse gas emission reductions: The prospect of atmospheric monitoring in polluted areas, Philos. T. Roy. Soc. A, 369, 1906-1924, 2011.

Popa, M. E., Vermeulen, A. T., van den Bulk, W. C. M., Jongejan, P. A. C., Batenburg, A. M., Zahorowski, W., and Röckmann, T.: $\mathrm{H}_{2}$ vertical profiles in the continental boundary layer: measurements at the Cabauw tall tower in The Netherlands, Atmos. Chem. Phys., 11, 6425-6443, doi:10.5194/acp-11-6425-2011, 2011.

Pui, D., Romaynovas, F., and Liu, B.: Experimental study of particle deposition in bends of circular cross section, Aerosol Sci. Tech., 7, 301-315, 1987.

Porstendörfer, J.: Properties and behaviour of radon and thoron and their decay products in the air, J. Aerosol. Sci., 25, 219-263, 1994.

Nazaroff, W. W.: Radon transport from soil to air, Rev. Geophys., 30, 137-160, 1992.

Reineking, A., Becker, K. H., and Porstendörfer, J.: Measurements of activity size distribution of the short-lived radon daughters in the indoor and outdoor environment, Radiat. Prot. Dosim., 24, 245-250, 1988.

Rosenfeld, M.: Modification of the Heidelberger Radon Monitor and first measurements, Diploma Thesis, Institut für Umweltphysik, Heidelberg University, 2010 (in German).

Schery, S. D. and Wasiolek, P. T.: A two-particle model and measurements of radon progeny near the earth's surface, J. Geophys. Res., 98, 22915-22923, 1993.
Schmithüsen, D., Chambers, S., Fischer, B., Gilge, S., Hatakka, J., Kazan, V., Neubert, R., Paatero, J., Ramonet, M., Schlosser, C., Schmid, S., Vermeulen, A., and Levin, I.: A European-wide ${ }^{222}$ radon and ${ }^{222}$ radon progeny comparison study, Atmos. Meas. Tech., 10, 1299-1312, doi:10.5194/amt-10-1299-2017, 2017.

Seinfeld, J. H. and Pandis, S. N.: Atmospheric chemistry and physics, from air pollution to climate change, 2nd Edn., John Wiley \& Sons, Inc., New York, 1203 pp., 2006.

Taguchi, S., Law, R. M., Rödenbeck, C., Patra, P. K., Maksyutov, S., Zahorowski, W., Sartorius, H., and Levin, I.: TransCom continuous experiment: comparison of ${ }^{222} \mathrm{Rn}$ transport at hourly time scales at three stations in Germany, Atmos. Chem. Phys., 11, 10071-10084, doi:10.5194/acp-11-10071-2011, 2011

von der Weiden, S.-L., Drewnick, F., and Borrmann, S.: Particle Loss Calculator - a new software tool for the assessment of the performance of aerosol inlet systems, Atmos. Meas. Tech., 2, 479-494, doi:10.5194/amt-2-479-2009, 2009.

Whittlestone, S. and Zahorowski, W.: Baseline radon detectors for shipboard use: development and deployment in the First Aerosol Characterization Experiment (ACE 1), J. Geophys. Res. 103, 16743-16751, 1998.

Willeke, K. and Baron, P. A. (Eds.): Aerosol Measurement - Principles, Techniques, and Applications, Van Nostrand Reinhold, New York, 2005.

Xia, Y., Sartorius, H., Schlosser, C., Stöhlker, U., Conen, F., and Zahorowski, W.: Comparison of one- and two-filter detectors for atmospheric ${ }^{222} \mathrm{Rn}$ measurements under various meteorological conditions, Atmos. Meas. Tech., 3, 723-731, doi:10.5194/amt-3723-2010, 2010.

York, D., Evensen, N. M., Martínez, M. L., and de Basabe Delgado, J.: Unified equations for the slope, intercept, and standard error of the best straight line, Am. J. Physics, 72, 367-375, 2004.

Zahorowski, W., Chambers, S., and Henderson-Sellers, A.: Groundbased ${ }^{222} \mathrm{Rn}$ observations and their application to atmospheric studies, J. Environ. Radioactiv., 76, 3-33, 2004. 